\title{
GUARANTEED INVESTMENT CONTRACTS: DISTRIBUTED AND UNDISTRIBUTED EXCESS RETURN
}

\author{
KRISTIAN R. MILTERSEN AND SVEIN-ARNE PERSSON
}

\begin{abstract}
Annual minimum rate of rcturn guarantces arc analyzed together with rules for the distribution of excess return, i.e., annual return above the guarantee. The set of, in a specific sense, fair contracts is charactcrized with and without a bonus account consisting of accumulated undistributed cxcess rcturn. A "paticnt" customer who is willing to transfer a sharc of the annual excess surplus to the bonus account and wait until the cxpiration of the contract to receive the balance of the bonus account may benefit from a seemingly more "favorable" set of fair contracts, than an "impatient" customer who wants as large a share as possible of the annual cxcess return credited to her account cach ycar.
\end{abstract}

\section{INTRODUCTION}

Currently differences between the banking and life insurance industries seem to vanish. Many bank products contain elements of insurance and vice versa. In particular, the focus of some life insurance products shift from benefits payable at a remote future time to the annual savings element.

The topic of this paper is an investment/savings plan or contract between two parties called the insurer and the customer. In life insurance similar contrants are known as unit-linked or equity-linked contracts. Apart from this resemblance no other insurance aspects are present. The contract specifies a benchmark return and an annual (periodic) minimum rate of return guarantee. The valuation of such guarantees has been analyzed by Persson and Aase (1997) and Miltersen and Persson (1997) under various term structure models and investment benchmarks. In this paper these guarantees are evaluated in connection with a surplus distribution mechanism, i.e., a rule for the distribution of the annual investment return above the guarantee between the insurer and the customer. We specially focus on the situation where the guarantee and the distribution rules are designed so that no additional upfront option premium is required for the guarantee. This is in contrast. with the two papers mentioned which disregard surplus distribution and concentrate on evaluating this option premium.

At date zero the customer deposits an amount $X$ into an account $A$ which is invested by the insurer for a period of $T$ years. The insurer promises the customer an annual rate of return on the account $A$ in

Date: January 1998. This version: March 22, 1999.

The paper was prescnted at the 4'th Nordic Symposium on Contingent Claims Analysis in Finance and Insurance, Copenhagen Business School, Copenhagen, Denmark. Comments from Knut Aasc, Anders Grosen, Mette Hansen, Bjarne Astrup Jensen, Peter Løchte Jørgensen, Jørgen Aase Nielsen, Mogens Steffensen, and other seminar participants were most appreciated. The first author gratefully acknowledges financial support of the Danish Natural and Social Science Research Councils and Danske Bank. Document typesct in LATEX. 
year $i$ equal to

$$
g_{i}+\alpha\left(\delta_{i}-g_{i}\right)^{+}
$$

where the constant $g_{i}$ is a specified minimum rate of return guarantee in year $i, \delta_{i}$ is the random rate of return of the specified benchmark portfolio in year $i$, and $\alpha \in[0,1]$ is the fraction of the positive excess rate of return which is credited to the customer's account.

In addition, the insurer operates with a bomus account, $B$. That is, if the annual rate of return on the benchmark portfolio in year $i, \delta_{i}$, exceeds the minimum guaranteed rate of return, $g_{i}$, a fraction, $\beta \in[0,1]$, of the excess rate of return is deposited into the bonus account. On the other hand, if the realized annual rate of return on the benchmark portfolio is less than the minimum guaranteed rate of return, then funds are transferred from the bonus account to the account $A$ to cover the guarantee. When the contract expires, the customer receives any positive balance on the bonus account, whereas the insurer covers a negative balance. In financial terms, the insurer has issued a (European) call option giving the customer the right to the amount on the bonus account for an exercise price of zero. By this mechanism the balance of the bonus account represents undistributed surplus.

In return for this call option the insurer receives the part of the excess rate of return that is neither distributed to the customer's account, $A$, nor to the bonus account, $B$. We denote the insurer's account by $C$. In total the entire return is distributed to the three accounts.

We assume that the insurer operates in a competitive market forcing abnormal profits to zero. In the specified contract the customer forsakes the return of the benchmark portfolio in return for the annual guarantees and the call option on the bonus account. The competitive market argument then states that the date zero market value of the sum of the accounts $A$ and $B$ is equal to the initial investment in the benchmark portfolio. If the date zero market values of the sum of the accounts $A$ and $B$ were greater than the initial investment in the benchmark portfolio, the customer could make arbitrary high profits by increasing the number of such contracts. In the opposite case, the insurer could make arbitrary high profits. Neither of these situations are consistent with any sensible economic model with a competitive market for these kinds of insurance contracts. The same argument is used by Briys and de Varenne (1997) also in the context of life insurance though analyzing different issues.

The central role of the insurer in our set-up is to serve as a financial intermediator. Instead of investing directly in the underlying benchmark portfolio, the insurer offers alternative investment possibilities based on the same underlying benchunark portfolio which may include an annual guarantee and a bonus account. In good years the insurer keeps part of the surplus, in bad years the insurer provides additional yield. ${ }^{1}$

\footnotetext{
${ }^{1}$ The role of the insurcr, namcly to distribute surplus from good to bad years, is then somewhat analogue to the famous
} English charactcr Robin Hood who notoriously distributed wcalth from rich to poor peoplc. 
Note carefully that the guarantee and the bonus account by construction have market value zero at the time of inception of the contract, i.e., it is a fair zero-sum game between the insurer and the customer.

An additional point concerns the paraneter $\alpha$. Although we focus on annual returns instead of benefits, a high $\alpha$ means that the return of the benchmark portfolio has a high impact on the annual return of the contract. This situation resembles equity-linked and unit-linked life insurance policies. In contrast, $\alpha=0$ corresponds to a deterministic rate of return of the contract which is the case for traditional life insurance contracts (distegarding bonus mechanisins).

In the Fall of 1998 a major Norwegian insurance company introduced a new savings product. It turns out as we demonstrate below that this product fits exactly into our model and thus may be analyzed within our framework.

The paper is organized as follows. Section 2 outlines the model and explains the cash flows between the three accounts. Section 3 treats the case of Gaussian return on the benchmark portfolio and deterministic short term interest rates. A closed form solution for the value of the customer's account is derived. The value of the bonus account is solved by Monte Carlo simulations. Corresponding values of annual minimum rate of return guarantees and the fractions of the excess return distributed to the customer's account and the bonus account are plotted for fair contracts. Finally, Section 4 concludes.

\section{THE MODEL}

The brief description of our model outlined in the Introduction only worked with the rates of return. In order to make the cash flows to the three accounts crystal clear we must write up the distribution of dollars and cents into the three accounts. We use the same symbols for the amounts on the accounts as earlier for the accounts themselves, i.e., the amount on account $A$ at the end of year $t$ is denoted $A_{t}$.

2.1. No Bonus Account. At first we will ignore the existence of the bonus account and only work with the customer's account, $A$, and the insurer's account, $C$. At the end of year $t$ the total amount on account $A$ can be written recursively using the amount on the account at the end of the preceding year as

$$
A_{t}=A_{t-1} e^{g_{t}+\alpha\left(\delta_{t}-g_{t}\right)^{+}} .
$$

'I'hat is, the balance at the end of year $t$ is simply the balance at the end of year $t-1$ with interest accrued according to the guaranteed rate, $g_{t}$, and a fraction of a positive excess rate of return. The initial amount, $A_{0}$, on this account equals the invested sum at date zero, $X$. Hence, $A_{t}$ can be written as

$$
A_{t}=X e^{\sum_{i=1}^{t}\left(g_{i}+\alpha\left(\delta_{i}-g_{i}\right)^{+}\right)} .
$$


The remaining amount is credited to the insurer's account, $C$. Hence, the amount on the account $C$ at the end of year $t$ can residually be determined as

$$
C_{t}=X e^{\sum_{i=1}^{t} \delta_{i}}-A_{t}
$$

The insurer is not actually required to invest the amount $X$ in the benchmark portfolio at date zero. The actual investment strategy followed by the insurer is not of any concern to the customer as long as the correct amount is credited to the account $A$. The correct amount is calculated on the basis of $X$ and the rate of return on the benchmark portfolio. However, for the purpose of finding the value, at date zero, of the different accounts we can assume (without loss of generality) that the insurer actually does invest the amount $X$ in the benchmark portfolio, as the following simple no-arbitrage argument shows: Suppose that there was an alternative investment strategy that would give a higher date zero value than the investment of the amount $X$ in the benchmark portfolio. Then any investor could create an arbitrage opportunity by shorting the amount $X$ in the benchmark portfolio and investing the money by following the alternative strategy.

As explained, the insurer operates in a competitive market implying that the date zero value of $C_{T}$ equals zero. If the date $t$ market value operator is denoted by $V_{t}(\cdot)$, we obtain the following restriction

$$
V_{0}\left(C_{T}\right)=0
$$

That is, the insurer gets a fair share of the excess rate of return on the benchmark portfolio for issuing the annual minimum rate of return guarantee for the customer's account, $A$. Combining Equations (2) and (3), we have

$$
X=V_{0}\left(X e^{\sum_{i=1}^{T} \delta_{i}}\right)=V_{0}\left(A_{T}\right)
$$

which imply, using Equation (1), that

$$
\left.V_{0}\left(\frac{A_{T}}{X}\right)=V_{0}\left(e^{\sum_{i=1}^{T}\left(g_{i}+\alpha\left(\delta_{i}-g_{i}\right)^{+}\right.}\right)\right)=1
$$

The final condition determines the relation between annual minimum rate of return guarantees over the years from date zero to the end of year $T,\left\{g_{i}\right\}_{i=1}^{T}$, and the fraction of the excess rate of return that the customer gets, $\alpha$, for the contracts offered by insurers operating in this competitive market.

2.2. The Bonus Account. We now introduce the bonus account, $B$. At the end of year $t$ the total amount on the bonus account, $B_{t}$, can be written recursively using the amount on the bonus account at 
the end of the preceding year as ${ }^{2}$

$$
B_{t}=B_{t-1}+A_{t-1}\left[\left(e^{\beta\left(\delta_{t}-g_{t}\right)^{+}}-1\right)-\left(e^{g_{t}}-e^{\delta_{t}}\right)^{+}\right]
$$

The first term in the bracket represents the share of year $t$ 's excess rate of return that is credited to the bonus account. The second term of the bracket represents the potential investment deficit in year $t$, i.e., if the rate of return realized is lower than the rate of return guaranteed, the deficit is subtracted from the bonus account and credited to the customer's account, $A$. Observe that the balance of the customer's account, $A$, is used as base. The initial balance of the account $B$ is zero. We can thus write $B_{t}$, for $t=1$, $\ldots, T-1$, as

$$
B_{t}=\sum_{i=1}^{t}\left[\left(e^{\mathcal{\beta}\left(\delta_{i}-g_{i}\right)^{+}}-1\right)-\left(e^{g_{i}}-e^{\delta_{i}}\right)^{+}\right] A_{i-1} .
$$

The insurer's promise to cover a potential deficit on this account at date $T$ is incorporated by the terminal condition

$$
B_{T}=\left(\sum_{i=1}^{T}\left[\left(e^{\beta\left(\delta_{i}-g_{i}\right)^{+}}-1\right)-\left(e^{g_{i}}-e^{\delta_{i}}\right)^{+}\right] A_{i-1}\right)^{+}
$$

In the presence of a bonus account the account $C$ is residually determined as

$$
C_{t}=X e^{\sum_{i=1}^{t} \delta_{i}}-A_{t}-B_{t}
$$

Note that the insurer's obligation to cover the potential deficit at date $T$ is already incorporated since $B_{T}=0$ in the case of a potential deficit and the deficit has, therefore, residually been transferred from the account $B$ to the account $C$.

The competitive market argument employed earlier again sets the condition $V_{0}\left(C_{T}\right)=0$, leading to the condition

$$
X=V_{0}\left(A_{T}\right)+V_{0}\left(B_{T}\right)
$$

to be satisfied by different combinations of $\alpha, \beta$, and $\left\{g_{i}\right\}_{i=1}^{T}$. Different combinations of $\alpha$ s and $\beta$ s give us different contracts. E.g., $\alpha=0$ resembles a standard life-insurance investment contract with a surplus distribution mechanism whereas $\beta=0$ resembles a full equity-linked life insurance contract without a surplus distribution mechanism. Moreover, any combination between these two extrenes are provided with both $\alpha$ and $\beta$ strictly positive.

\footnotetext{
${ }^{2}$ Note that there are no interest payments on the amount of the bonus account. It is a modeling issue whether one prefers that the amount of the bonus account earns interest or not. The insurer does not benefit from these missing interest payments at the expense of the customer since we use the competitive market argument to drive the valuc of the insurer's claim to zero. We would have used exactly the same argument if there had been interest payments on the bonus account. Hence the result would simply have been a different guaranteed rate of return, ceteris paribus.
} 


\section{Solutions in the Gaussian Case with Deterministic Interest Rates}

Assume that we have a constant interest rate $r$ and that the annual rate of return from the benchmark portfolio, $\delta_{i}$, is normally distributed and independent over different years. Hence $\delta$ can be modeled (under an equivalent martingale measure $Q$ ) as

$$
\delta_{t}=r-\frac{1}{2} \sigma^{2}+\sigma\left(W_{t}-W_{t-1}\right),
$$

where $\sigma$ is the volatility of the rate of return on the benchmark portfolio and $W$ is a standard Wiener process under the measure $Q$. Note that we have implicitly assumed that there are no dividend payments ${ }^{3}$ on the benchmark portfolio since the drift is equal to the short term interest rate. The return on the benchmark portfolio follows the process in Equation (4) if, e.g., we assume that the price process of the benchmark portfolio follows a standard geometric Brownian motion as, e.g., in the Black-Scholes model, cf. Black and Scholes (1973) or Merton (1973).

3.1. The Value of the Account $A$. In order to find the date zero value of the customer's account, $A$, from Equation (1) for a given annual minimum rate of return guarantee, $\left\{g_{i}\right\}_{i=1}^{T}$, and the fraction of the excess rate of return that the customer gets, $\alpha$, we will evaluate

$$
\begin{aligned}
V_{0}\left(\frac{A_{T}}{X}\right) & =V_{0}\left(e^{\sum_{i=1}^{T}\left(g_{i}+u\left(\delta_{i}-y_{i}\right)^{+}\right)}\right) \\
& =E^{Q}\left[e^{-r T} e^{\sum_{i=1}^{T}\left(g_{i}+\alpha\left(\delta_{i}-g_{i}\right)^{+}\right)}\right] \\
& =E^{Q}\left[e^{-r T} e^{\sum_{i=1}^{T}\left(g_{i} \vee\left(\alpha \delta_{i}+(1-\alpha) g_{i}\right)\right)}\right] \\
& =E^{Q}\left[e^{-r T} e^{\left.\sum_{i=1}^{T}\left(\left(\alpha g_{i} \vee \alpha \delta_{i}\right)+(1-\alpha) g_{i}\right)\right)}\right] \\
& =E^{Q}\left[e^{-r T} e^{(1-\alpha) \sum_{i=1}^{T} g_{i}} e^{\sum_{i=1}^{T}\left(\alpha g_{i} \vee \alpha \delta_{i}\right)}\right] \\
& =e^{(1-\alpha) \sum_{i=1}^{T} g_{i}} \prod_{i=1}^{T} E^{Q}\left[e^{-r} e^{\left(\alpha g_{i} \vee \alpha \delta_{i}\right)}\right] \\
& =e^{(1-\alpha) \sum_{i=1}^{T} g_{i}} \prod_{i=1}^{T} E^{Q}\left[e^{-r}\left(e^{\alpha g_{i}} \vee e^{\alpha \delta_{i}}\right)\right] .
\end{aligned}
$$

In order to evaluate $E^{Q}\left[e^{-r}\left(e^{\alpha g_{i}} \vee e^{\alpha \delta_{i}}\right)\right]$ from Equation (5), we make the following observation

$$
\begin{aligned}
E^{Q}\left[e^{-\tau}\left(e^{\alpha g_{i}} \vee e^{\alpha \delta_{i}}\right)\right] & =e^{-\tau} E^{Q}\left[\left(e^{\alpha \delta_{i}}-e^{\alpha q_{i}}\right)^{+}+e^{\alpha g_{i}}\right] \\
& =e^{-\tau} E^{Q}\left[\left(e^{\alpha \delta_{i}}-e^{\alpha g_{i}}\right)^{+}\right]+e^{\alpha g_{i}-\tau} .
\end{aligned}
$$

\footnotetext{
${ }^{3}$ An cquivalent interpretation is that potential dividends on the assets included in the benchmark portfolio are immodiately reinvested into the benchunark portfolio.
} 
Hence, we have the value of a European call option on a modified underlying security with payoff $e^{\alpha \delta_{i}}$ at the maturity of the option. The value of this modified underlying security is

$$
e^{-r} E^{Q}\left[e^{\alpha \delta_{i}}\right]=e^{-r} e^{\alpha\left(r-\frac{1}{2} \sigma^{2}\right)+\frac{1}{2} \alpha^{2} \sigma^{2}}=e^{(\alpha-1)\left(r+\frac{1}{2} \alpha \sigma^{2}\right)}
$$

and its volatility is $\alpha \sigma$. Therefore, we can evaluate

$$
e^{-r} E^{Q}\left[\left(e^{\alpha \delta_{i}}-e^{\alpha g_{i}}\right)^{+}\right]=e^{(\alpha-1)\left(r+\frac{1}{2} \alpha \sigma^{2}\right)} \Phi\left(\frac{r-g_{i}-\frac{1}{2} \sigma^{2}+\alpha \sigma^{2}}{\sigma}\right)-e^{\alpha g_{i}-r} \Phi\left(\frac{r-g_{i}-\frac{1}{2} \sigma^{2}}{\sigma}\right)
$$

using the Black and Scholes (1973) formula. Here $\Phi$ denotes the cumulative distribution function of the standard normal distribution. If the reader is uncomfortable with our economic argument, the result can also be derived by brute force evaluation of the expectation. Thus, from Equation (6),

$$
E^{Q}\left[e^{-r}\left(e^{\alpha g_{i}} \vee e^{\alpha \delta_{i}}\right)\right]=e^{(\alpha-1)\left(r+\frac{1}{2} \alpha \sigma^{2}\right)} \Phi\left(\frac{r-g_{i}-\frac{1}{2} \sigma^{2}+\alpha \sigma^{2}}{\sigma}\right)+e^{\alpha g_{i}-r} \Phi\left(\frac{g_{i}-r+\frac{1}{2} \sigma^{2}}{\sigma}\right) .
$$

Finaliy, from Equation (5),

$$
V_{0}\left(\frac{A_{T}}{X}\right)=\prod_{i=1}^{T}\left(e^{(1-\alpha)\left(g_{i}-r-\frac{1}{2} \alpha \sigma^{2}\right)} \Phi\left(\frac{r-g_{i}-\frac{1}{2} \sigma^{2}+\alpha \sigma^{2}}{\sigma}\right)+e^{g_{i}-r} \Phi\left(\frac{g_{i}-r+\frac{1}{2} \sigma^{2}}{\sigma}\right)\right),
$$

which gives a closed form solution for the date zero value of the account $A$.

Assuming that the annual minimum rate of return guarantee is the same each year, i.e., $g_{i}=g$, for all $i$. we have depicted corresponding values of $\alpha$ and annual minimum rate of return guarantees, $g$, that provide a date zero value of the account $A$ equal to one in Figure 1. Hence, Figure 1 depicts combinations of $\alpha s$ and annual minimum rate of return guarantees offered by insurers in our competitive market. In this contract the entire surplus that is distributed to the customer is distributed annually. Not surprisingly, an increase of the volatility of the benchmark return lowers the guaranteed annual minimum rate of return to the customer, ceteris paribus.

Example 3.1. The bank division (Gjensidige Bank AS) of a Norwegian insurance company recently (September 1998) offered a product very similar to the one described above. The investment period is 8 years $(T=8)$. The annual minimum rate of return guarantee is $g_{i}=0 \%$. The underlying benchmark portfolio is an arithrnetric average of a selected series of national stock indices from various European stock exchanges. The sales brochure indicate an $\alpha$ in the range 50-60\%. The amount to investment, $X$, is at least NOK 10,000. ${ }^{4}$ For this produrt Equation (7) reduces to

$$
V_{0}\left(\frac{A_{T}}{X}\right)=\left(e^{(\alpha-1)\left(r+\frac{1}{2} \alpha \sigma^{2}\right)} \Phi\left(\frac{r-\frac{1}{2} \sigma^{2}+\alpha \sigma^{2}}{\sigma}\right)+e^{-\tau} \Phi\left(\frac{-r+\frac{1}{2} \sigma^{2}}{\sigma}\right)\right)^{T} .
$$

\footnotetext{
${ }^{4}$ From this amount adrninistrative expenses in the rarge $0.5-2.5 \%$ is subtracted. In this treatrnent, we disregard administrative experses and for this particular product we interpret them as such and not as an additional upfront payment charyed for the financial risk.
} 


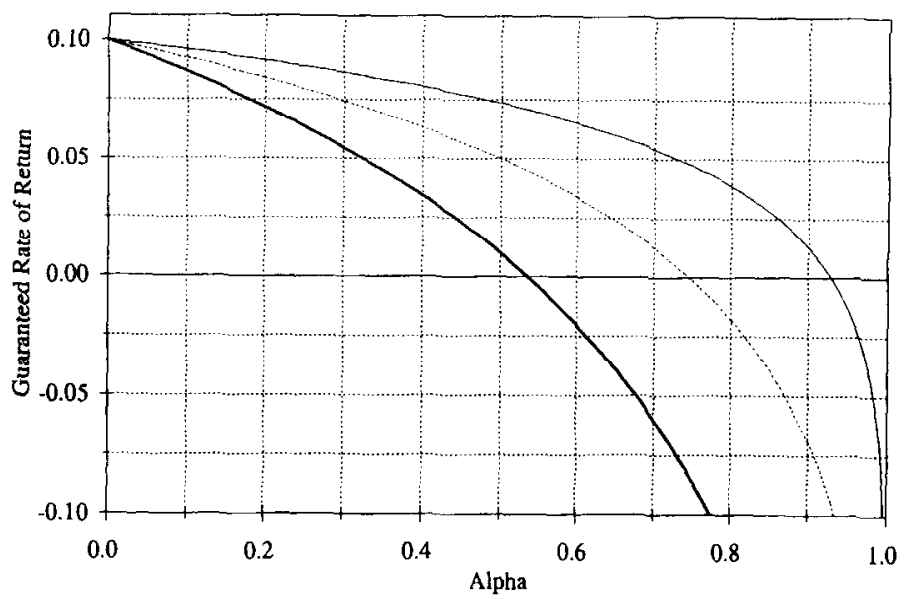

\section{Sigma $=0.1 \cdots \ldots . .$. Sigma $=0.2-$ Sigma $=0.4$}

FIgure 1. Corresponding values of $\alpha$ and $g$ for three different values of $\sigma, \beta=0$, and $r=0.1$.

The requinement that $V_{0}\left(\frac{A_{T}}{X}\right)=1$ is thus equivalent with the rondition

$$
e^{(\alpha-1)\left(r+\frac{1}{2} \alpha \sigma^{2}\right)} \Phi\left(\frac{r-\frac{1}{2} \sigma^{2}+\alpha \sigma^{2}}{\sigma}\right)+e^{-r} \Phi\left(\frac{-r+\frac{1}{2} \sigma^{2}}{\sigma}\right)=1 .
$$

In Figure 2 we have plotted combinations of $\alpha$ and $\sigma$ satisfying this condition under the assumption that $r=0.08$ (roughly the interest rate level in Norway in September 1998).

3.2. The Value of the Account $B$. We now assume that the anrual minimum rate of return guarantee is the same each year, i.e., $g_{i}=g$, for all $i$. Denote

$$
\left.\pi_{A}(T)=V_{0}\left(\frac{A_{T}}{X}\right)=V_{0}\left(e^{\sum_{i=1}^{T}\left(g_{i}+\alpha\left(\delta_{i}-g_{i}\right)^{+}\right.}\right)\right) .
$$

First we we consider the B account at intermediate dates, i.e. before the terminal date $T$. The similar market value, at date zero, for the account $B_{t}$, for $t<T$ is

$$
V_{0}\left(\frac{B_{t}}{X}\right)=\pi_{H}(1) e^{-r t} \sum_{i=1}^{t} \pi_{A}(i-1) e^{r i}
$$




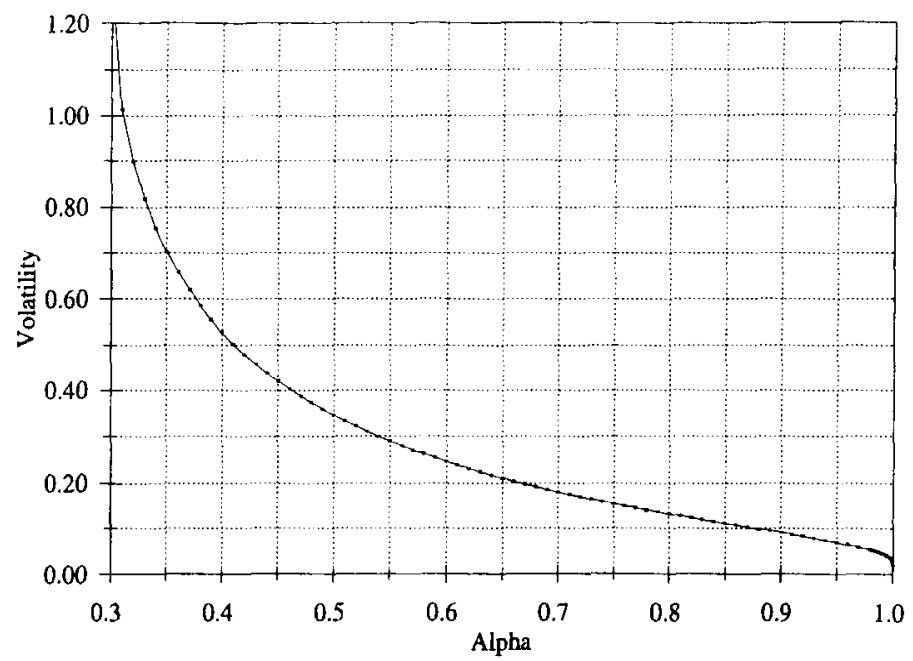

Figure 2. Corresponding values of $\alpha$ and $\sigma$ for $g=0, \beta=0$, and $r=0.08$.

where

$$
\begin{aligned}
\pi_{H}(1)= & e^{(\beta-1)\left(r+\frac{1}{2} \beta \sigma^{2}\right)-\beta g} \Phi\left(\frac{r-g-\frac{1}{2} \sigma^{2}+\beta \sigma^{2}}{\sigma}\right) \\
& +e^{-r}\left(\Phi\left(\frac{g-r+\frac{1}{2} \sigma^{2}}{\sigma}\right)\left(1-e^{g}\right)-1\right)+\Phi\left(\frac{g-r-\frac{1}{2} \sigma^{2}}{\sigma}\right) .
\end{aligned}
$$

Here $\pi_{H}(1)$ is the market value at time zero of the difference between the payoffs $e^{\beta\left(\delta_{1}-g\right)^{+}}-1$ and $\left(e^{g}-e^{\delta}\right)^{+}$expiring at time 1. The first payoff is similar to a call option with exercise price 1 , but the price process of the underlying asset is modified. The second payoff is simply the payoff of a put option with exercise price $e^{g}$.

However, it is harder to find the date zero value of the balance of account $B$ at date $T$ as a closed form expression because of the terminal condition, the + operator on $B_{T}$. As a first step to this end we calculate the date $T-1$ market value of the $B_{T}$ and denote it $V_{T-1}\left(B_{T}\right)$.

We start by rewriting $B_{T}$ in terms of $A_{T-1}$ and $B_{T-1}$ as

$$
B_{T}=\left(B_{T-1}+A_{T-1}\left(e^{\beta(\delta-g)^{+}}-1-\left(e^{g}-e^{\delta}\right)^{+}\right)\right)^{+}
$$


where $\delta=\delta_{T}$ for notational simplicity. By splitting the payoff according to whether the guarantee becomes effective in the final period, i.e., whether $\delta>g$ or $\delta<g$, we obtain

$$
\begin{aligned}
B_{T}= & \left(A_{T-1} e^{\beta(\delta-g)}-\left(A_{T-1}-B_{T-1}\right)\right)^{+} 1_{\{\delta>9\}} \\
& +\left(A_{T-1} e^{\delta}-\left(A_{T-1} e^{g}-B_{T-1}\right)\right)^{+} 1_{\{\delta<g\}}
\end{aligned}
$$

Each of these terms resembles the payoff of a call option. We proceed by substituting indicator functions for the maximum operators

$$
\begin{aligned}
& B_{T}=\left(A_{T-1} e^{\beta(\delta-g)}-\left(A_{T-1}-B_{T-1}\right)\right) \times \\
& \left(1_{\left\{\delta>g+\frac{1}{1} \ln \left(1-\frac{B_{T .1}}{A_{T .1}}\right)\right\}} 1_{\left\{B_{T .2}<0\right\}}+1_{\{\delta>g\}} 1_{\left\{B_{T .1}>0\right\}}\right) \\
& +\left(A_{T-1} e^{\delta}-\left(A_{T-1} e^{g}-B_{T-1}\right)\right) \times \\
& \left(1_{\left\{\ln \left(\exp (g)-\frac{B_{T .1}}{A_{T}, 1}\right)<\delta<g\right\}} 1_{\left\{0<B_{T, 1}<A_{T .1} \exp (g)\right\}}+1_{\{\delta<g\}} 1_{\left\{B_{T, 1}>A_{T .1} \exp (g)\right\}}\right) .
\end{aligned}
$$

Since $A_{T-1}$ and $B_{T-1}$ are known at time $T-1$, it is straightforward to calculate $V_{T-1}\left(B_{T}\right)$. For notational simplicity we define two functions

$$
d_{x}=\frac{1}{\sigma}\left(r-x-\frac{1}{2} \sigma^{2}+\beta \sigma^{2}\right)
$$

and

$$
e_{x}=\frac{1}{\sigma}\left(x-r-\frac{1}{2} \sigma^{2}\right)
$$

Moreover, we define

$$
K=\ln \left(e^{g}-\frac{B_{T-1}}{A_{T-1}}\right)
$$

and

$$
L=g+\frac{1}{\beta} \ln \left(1-\frac{B_{T-1}}{A_{T-1}}\right) .
$$




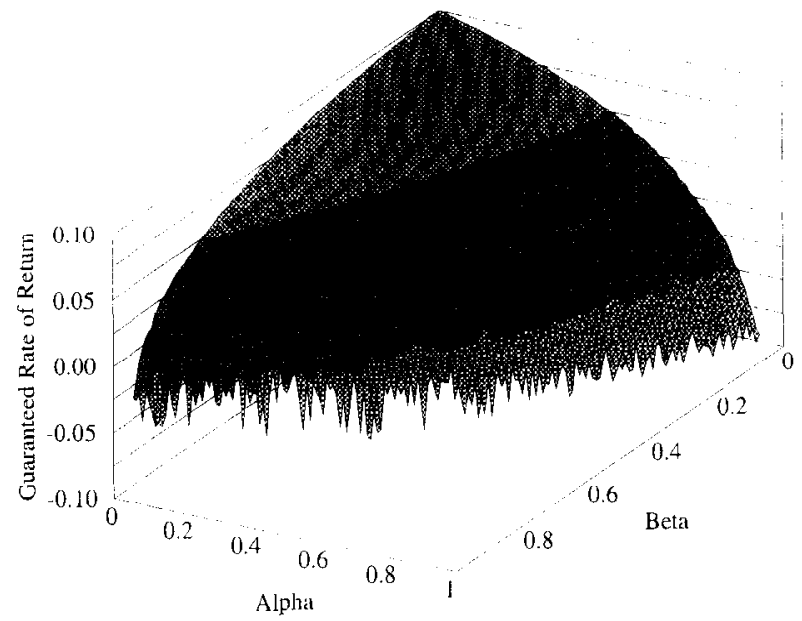

FIGURE 3. Corresponding values of $\alpha, \beta$, and $g$ for $r=0.1, T=2$, and $\sigma=0.2$.

Then we calculate

$$
\begin{aligned}
V_{T-1}\left(B_{T}\right)= & 1_{\left\{B_{T, 1} \geq 0\right\}}\left(A_{T-1} e^{(\beta-1)\left(r+\frac{1}{2} \sigma^{2} \beta\right)-\beta g} \Phi\left(d_{g}\right)-\left(A_{T-1}-B_{T-1}\right) e^{-\tau} \Phi\left(d_{g}-\beta \sigma\right)\right) \\
& +1_{\left\{B_{T, 1} \geq 0\right\}}\left(A_{T-1} \Phi\left(e_{g}\right)-\left(A_{T-1} e^{g}-B_{T-1}\right) e^{-\tau} \Phi\left(e_{g}+\sigma\right)\right) \\
& -1_{\left\{0 \leq B_{T}, 1<A \operatorname{cxp}(g)\right\}}\left(A_{T-1} \Phi\left(e_{K}\right)-\left(A_{T-1} e^{g}-B_{T-1}\right) e^{-r} \Phi\left(e_{K}+\sigma\right)\right) \\
& +1_{\left\{B_{T, 1}<0\right\}}\left(A_{T-1} e^{(\beta-1)\left(r+\frac{1}{2} \sigma^{2} \beta\right)-\beta g} \Phi\left(d_{L}\right)-\left(A_{T-1}-B_{T-1}\right) e^{-\tau} \Phi\left(d_{L}-\beta \sigma\right)\right) .
\end{aligned}
$$

In order to calculate the date zero value of the $\mathrm{B}$ account including the terminal condition we turn to numerical methods. Since $V_{0}\left(B_{T}\right)=V_{0}\left(V_{T-1}\left(B_{T}\right)\right)$ the above closed form solution can be used to increase speed and precision in the numerical methods.

To find $V_{0}\left(B_{T}\right)$, we have implemented a simulation algorithm. For $T=2$ (years), $r=0.1$, and $\sigma=0.2$ we have in Figure 3 depicted combinations of $\alpha \mathrm{s}, \beta \mathrm{s}$, and annual minimum rate of return guarantees offered by insurers in our competitive market. That is, on top of the simulation algorithm we have a numerical search algorithm searching for combinations of $g, \alpha$, and $\beta$ such that the sum of the value of accounts $A$ and $B$ is equal to one. Since it is difficult to get exact readings from the three-dimensional figure (Figure 3), we have also made a couple of two-dimensional cuts of this figure: We have depicted four cuts for fixed values of $\beta$ in Figure 4 and likewise four cuts for fixed values of $\alpha$ in Figire 5 . 


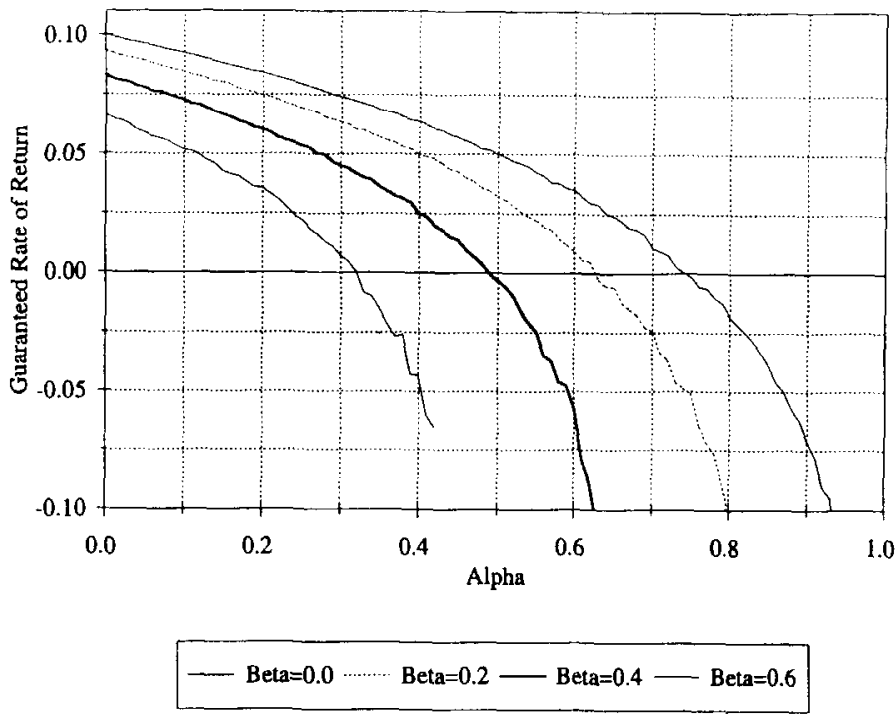

Figure 4. Corresponding values of $\alpha$ and $g$ for four different values of $\beta, r=0.1, T=2$, and $\sigma=0.2$.

First note that $\beta=0$ is equivalent to the case with no bonus arcount. Hence, the curve for $\beta=0$ in Figure 4 should be identical with the curve for $\sigma=0.2$ in Figure 1 . This can be confirmed by comparing Figures 1 and 4. Simultaneously, this indicates the accuracy of the implemented Monte Carlo simulation method.

Second note that by comparing the curve for $\beta=0$ in Figure 4 and the curve for $\alpha=0$ in Figure 5 for a given fraction of the excess return, the insurer offers a higher guaranteed annual minimum rate of return to a customer who places the return on a bonus account than to a customer who wants her return credited to her own account annually, ceteris paribus. Hence, it seems as if the more "patient" customer gets a better contract than the "impatient" customer. However, this is not the case since both contracts are fair in terms of market values. The reason is that (i) if the excess return is credited to the bonus account, the amount can be used in a later year to cover the guarantee if the benchmark rate of return is below the guaranteed annual minimum rate of return. This is not possible if the excess return is credited annually to the customer's account. Moreover, (ii) if the excess return is credited to the customer's account annually, the amount that the annual minimum rate of return guarantee covers is increased compared to the case where the excess return is credited to the bonus account, ceteris paribus. 

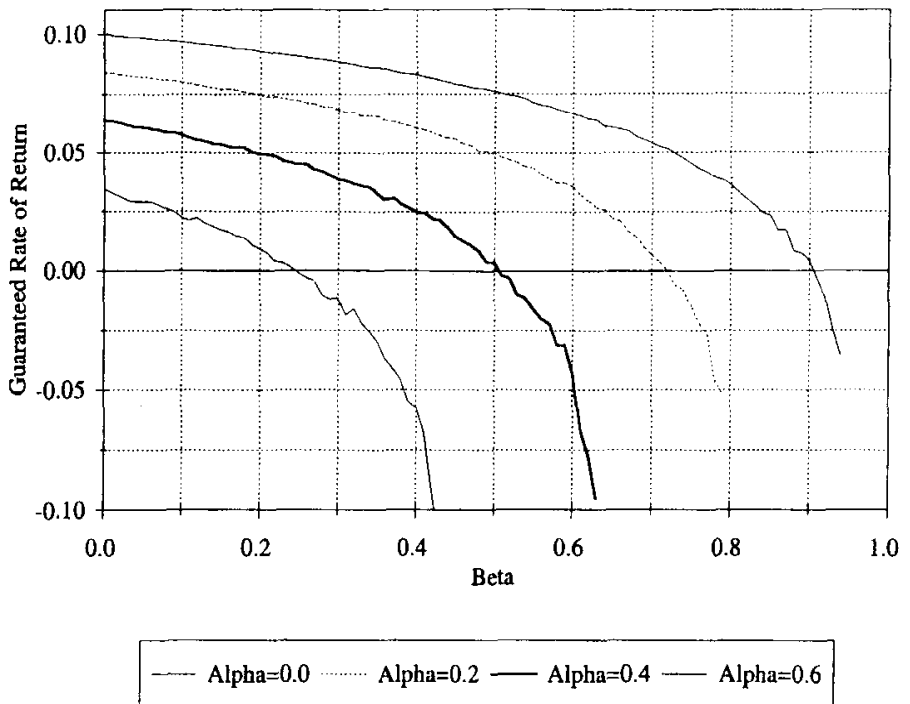

Figure 5. Corresponding values of $\beta$ and $g$ for four different values of $\alpha, r=0.1, T=2$, and $\sigma=0.2$.

With some diligence, this effect can also be studied from the other curves in Figures 4 and 5 . Compare, e.g., the curve for $\beta=0.2$ in Figure 4 and the curve for $\alpha=0.4$ in Figure 5. Both curves indicate that a customer who wants fourty percent of her excess return credited to her own account annually and in addition twenty percent credited to her bonus account is offered an annual minimum rate of return guarantee of five percent annually. By following both curves to the right we see that the customer has to give up more of her guaranteed annual minimum rate of return if she wants to increase the fraction of the excess return credited to her own account than if she wants to increase the fraction of the excess return credited to her bonus account, ceteris paribus. On the other hand, by following both curves to the left we see that the customer can increase her guaranteed annual minimum rate of retum more if she accepts to reduce the fraction of the excess return credited to her own account than if she reduces the fraction of the excess return credited to her boms account, ceteris paribus.

We have also depicted other parameter values in the following figures. In Figures 6-11 we have varied $\sigma$. Figures 6-8 correspond to a reduction of $\sigma$ from 0.2 in our base example to 0.1 and Figures 9-11 correspond to an increase of $\sigma$ from 0.2 to 0.4 . Again $\beta=0$ is equivalent to the case with no bonus account implying that the curves for $\beta=0$ in Figures 7 and 10 should be identical to the corresponding 


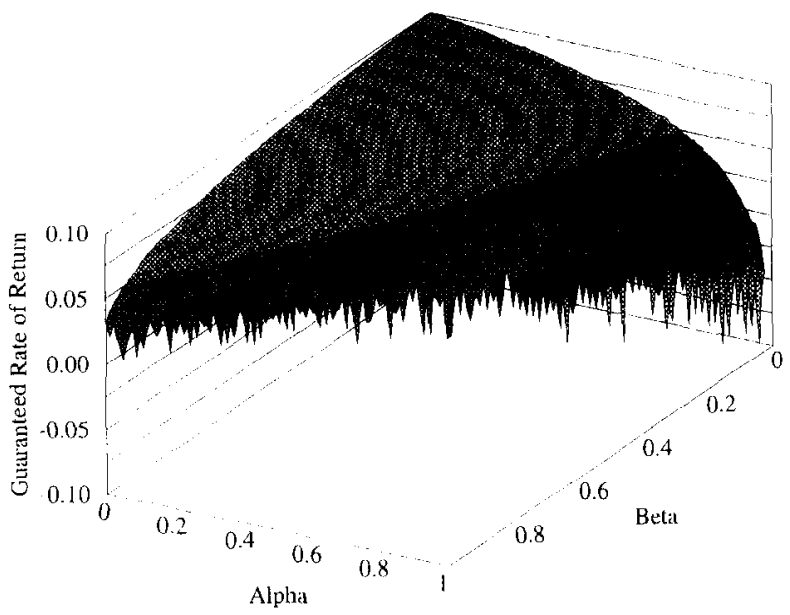

FIGURE 6. Corresponding values of $\alpha, \beta$, and $g$ for $r=0.1, T=2$, and $\sigma=0.1$.

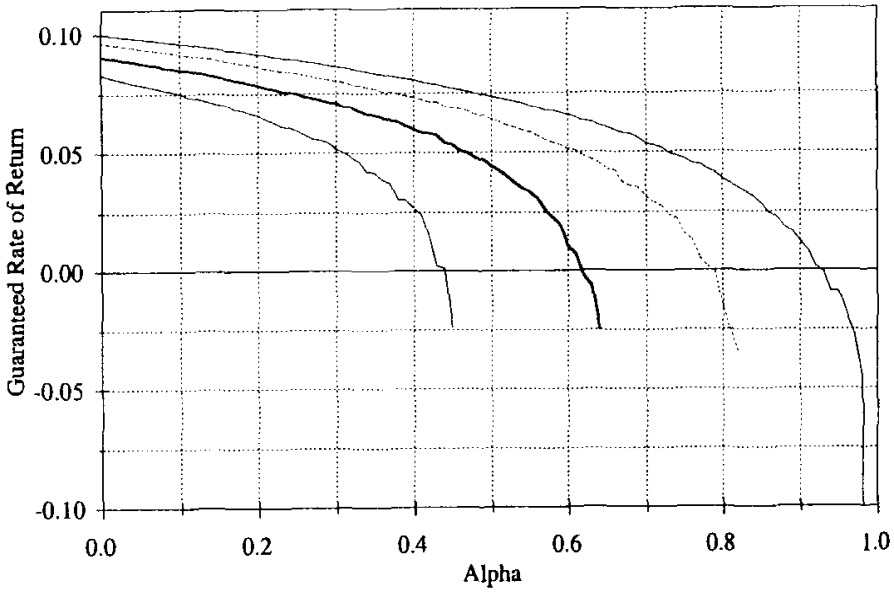

Beta $=0.0 \cdots \cdots$ Beta $=0.2-$ Beta $=0.4-$ Beta $=0.6$

FIGURE 7. Corresponding values of $\alpha$ and $g$ for four different values of $\beta, r=0.1, T=2$, and $\sigma=0.1$. 
GUARANTEED INVESTMENT CONTRACTS: DISTRIBUTED AND UNDISTRIBUTED EXCESS RETURN

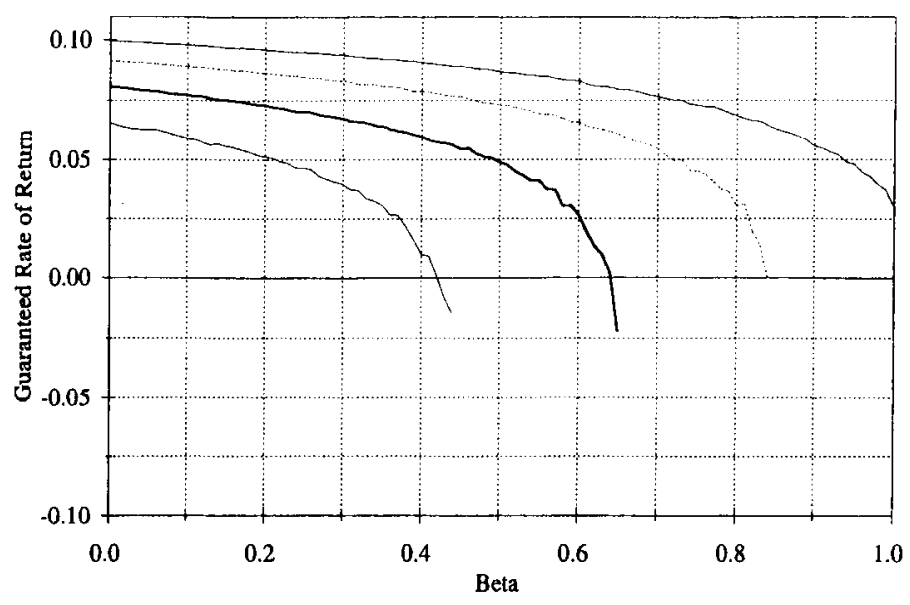

Alpha $=0.0 \cdots \ldots \ldots$ Alpha $=0.2-$ Alpha $=0.4-$ Alpha $=0.6$

FIGURE 8. Corresponding values of $\beta$ and $g$ for four different values of $\alpha, r=0.1, T=2$, and $\sigma=0.1$.

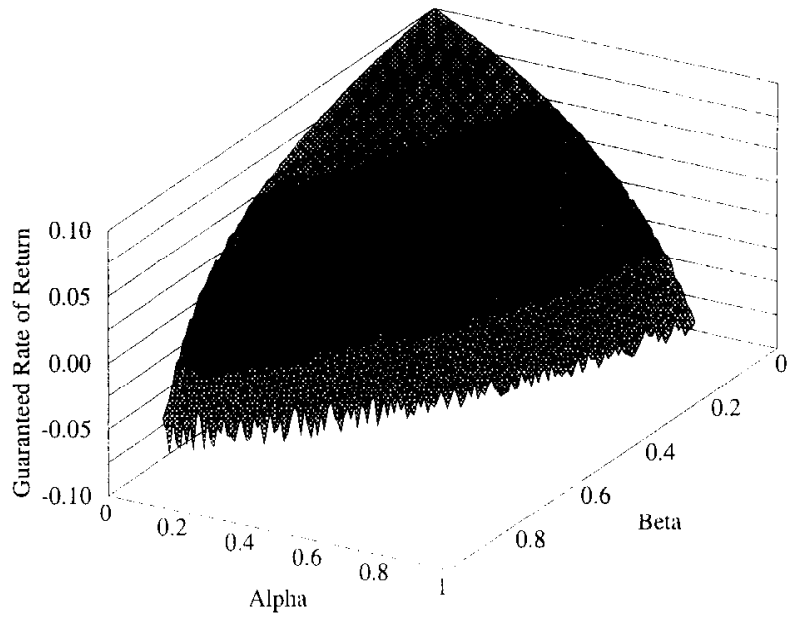

Figure 9. Corresponding values of $\alpha, \beta$, and $g$ for $r=0.1, T=2$, and $\sigma=0.4$. 

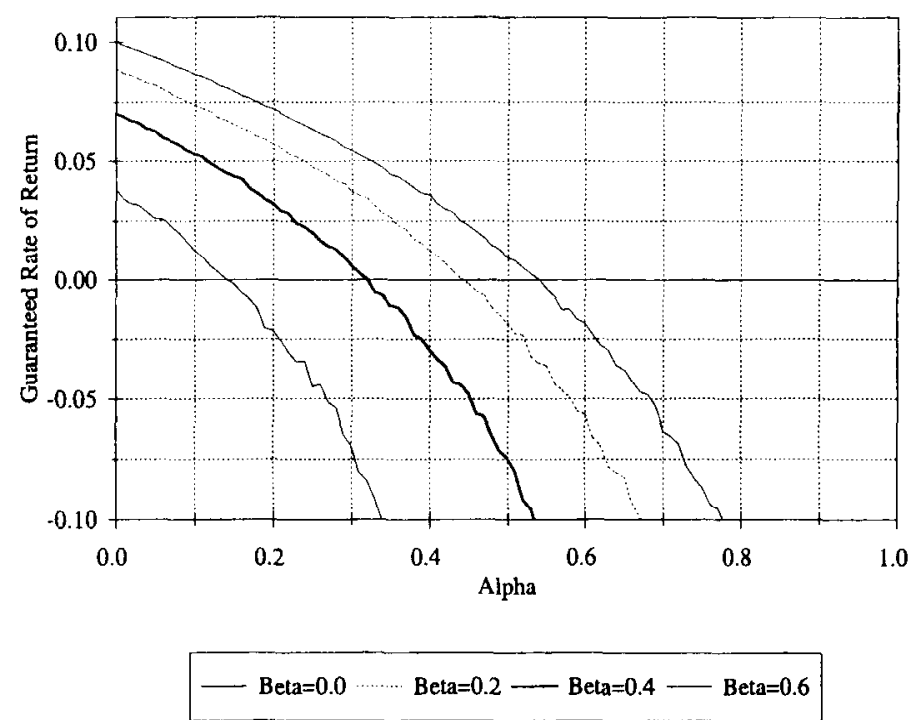

FiguRE 10. Corresponding values of $\alpha$ and $g$ for four different values of $\beta, r=0.1$, $T=2$, and $\sigma=0.4$.

curves for $\sigma=0.1$ and $\sigma=0.4$ in Figure 1. Hence, comparing Figures 1, 7, and 10 provides an indication of the accuracy of the implemented Monte Carlo simulation method.

Comparing Figures 6, 3, and 9; Figures 7, 4, and 10; and Figures 8, 5, and 11 we see the same pattern as in Figure 1, namely that an increase of the volatility of the benchmark return lowers the guaranteed anntial minimum rate of return to the customer, ceteris paribus.

In Figures 12-17 we have reset $\sigma$ to the base level of 0.2 and instead extended the number of periods from two in our base example to three and four (years). Figures 12-14 correspond to a three year contract whereas Figures 15-17 correspond to a four year contract. Again $\beta=0$ is equivalent to the case with no bonus account implying that the curves for $\beta=0$ in Figures 13 and 16 should be identical to the curve for $\sigma=0.2$ in Figure 1. Therefore, by comparing Figures 1, 13, and 16 we have an indication of the accuracy of the implemented Monte Carlo simulation method.

Comparing Figures 3,12, and 15; Figures 4, 13, and 16; and Figures 5, 14, and 17 we see that the effect that the insurer offers a higher annual minimum rate of return guarantee to a customer who places the excess return on a bonus account than to a customer who wants the excess return credited to her account annually is increased as the number of periods is increased, ceteris paribus. This is so because (i) with more periods the bonus account works much better as a buffer between periods with excess return 


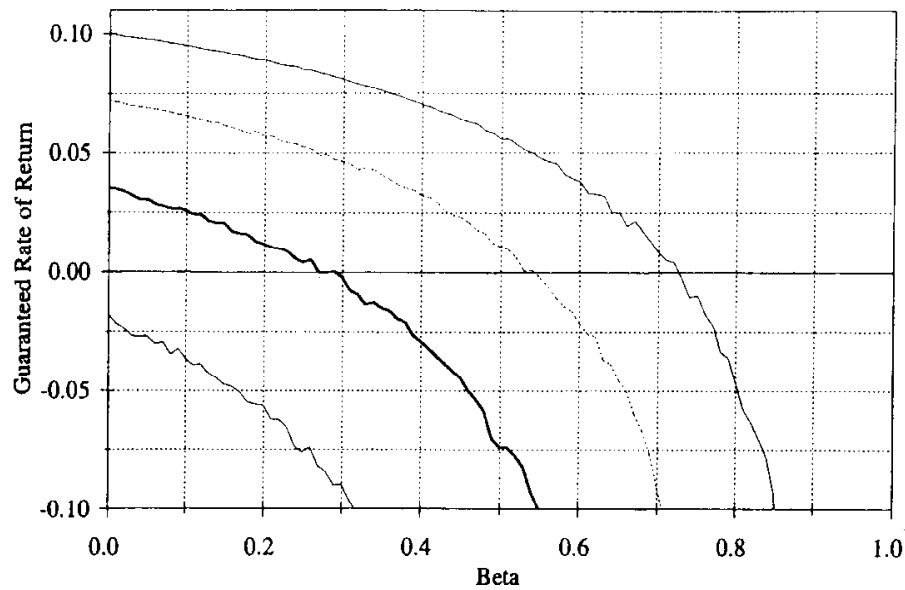

$$
\text { Alpha }=0.0 \cdots \cdots \text { Alpha }=0.2 \longrightarrow \text { Alpha }=0.4-\text { Alpha }=0.6
$$

Figure 11. Corresponding values of $\beta$ and $g$ for four different values of $\alpha, r=0.1$, $T=2$, and $\sigma=0.4$.

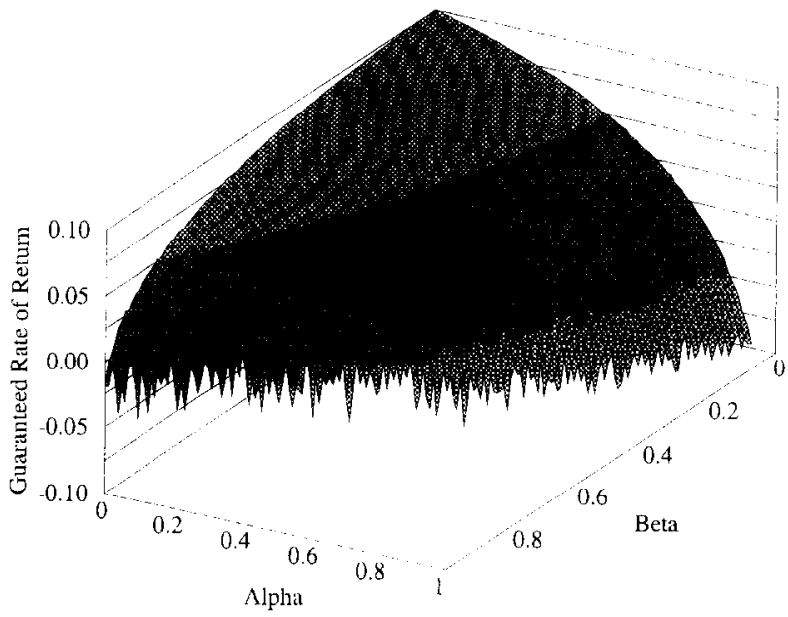

Figure 12. Corresponding values of $\alpha, \beta$, and $g$ for $r=0.1, T=3$, and $\sigma=0.2$. 

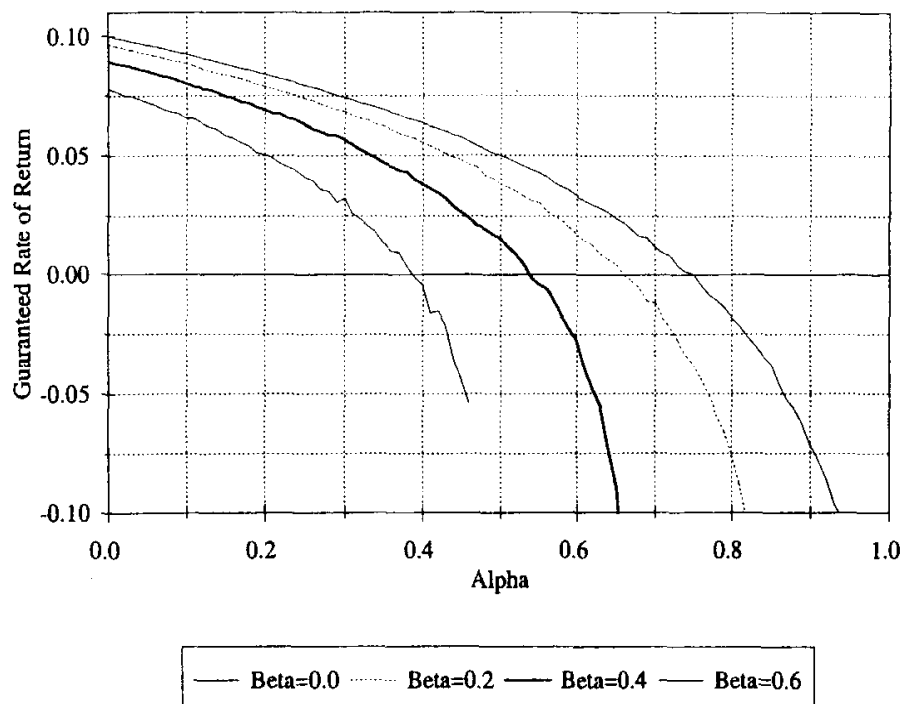

Figure 13. Corresponding values of $\alpha$ and $g$ for four different values of $\beta, r=0.1$, $T=3$, and $\sigma=0.2$.

and periods where the guarantee becomes effective. This de facto lowers the volatility of the option issued by the insurer. Moreover, (ii) with more periods the extra amount that is guaranteed for the customer who wants her excess return credited to her account annually is increased compared to the customer who wants her excess return credited to her bonus account.

\section{CONCLUDING REMARKS}

We have presented a framework which we believe constitutes a suitable starting point for analyzing the connection between annual guarantees and the distribution of surplus. The contract we study is close to many real world contracts and further properties of such contracts can easily be included in our set-up and analyzed using our simulation method. E.g., we can easily include mortality risk ${ }^{5}$ and annual premium payments instead of a single lump sum payment. It is also straightforward to include, e.g., stochastic interest rates in our framework.

In this paper we have only considered individual undistributed surplus modeled by the customer's own bonus account. In many real-life life insurance contracts the undistributed surplus mechanism

\footnotetext{
${ }^{5}$ Under the assumption that the insurer has a large pool of customers with independent mortality risk, which is also uncorrelated with the return on the benchmark portfolio, a simple argument based on the law of large numbers can be applied to climinate the mortality risk as seen from the insurcr's point of view and, therefore, the insurer would be willing to provide life-insurance contracts based on the assumption that the mortality is detcrninistic.
} 


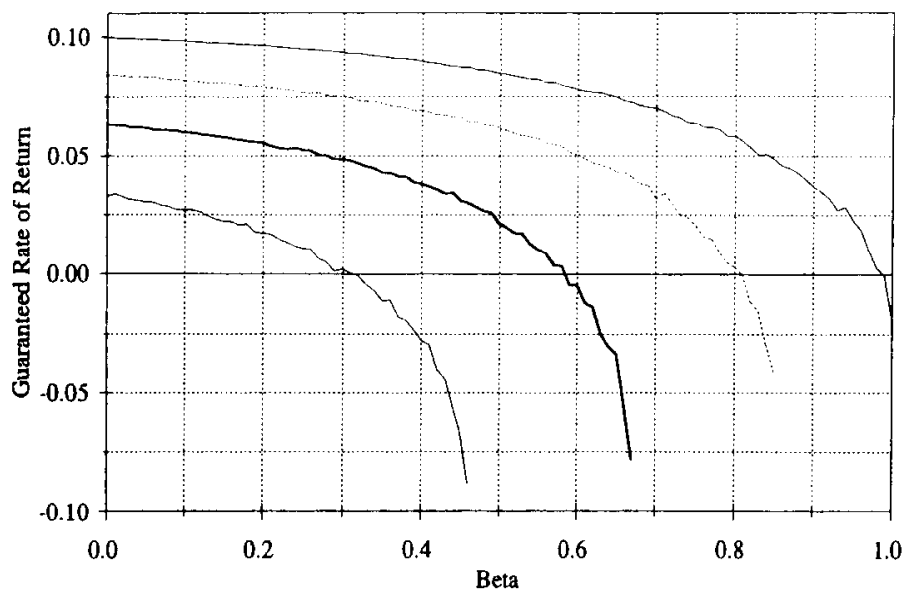

Alpha $=0.0 \quad \cdots \cdots . .$. Alpha $=0.2-$ Alpha $=0.4-$ Alpha $=0.6$

FIGURE 14. Corresponding values of $\beta$ and $g$ for four different values of $\alpha, r=0.1$, $T=3$, and $\sigma=0.2$.

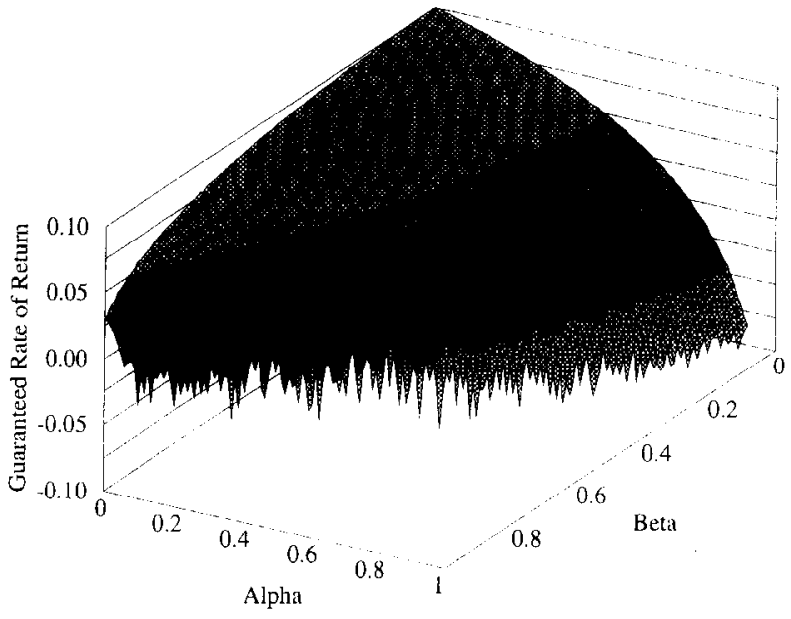

Figure 15. Corresponding values of $\alpha, \beta$, and $g$ for $r=0.1, T=4$, and $\sigma=0.2$. 


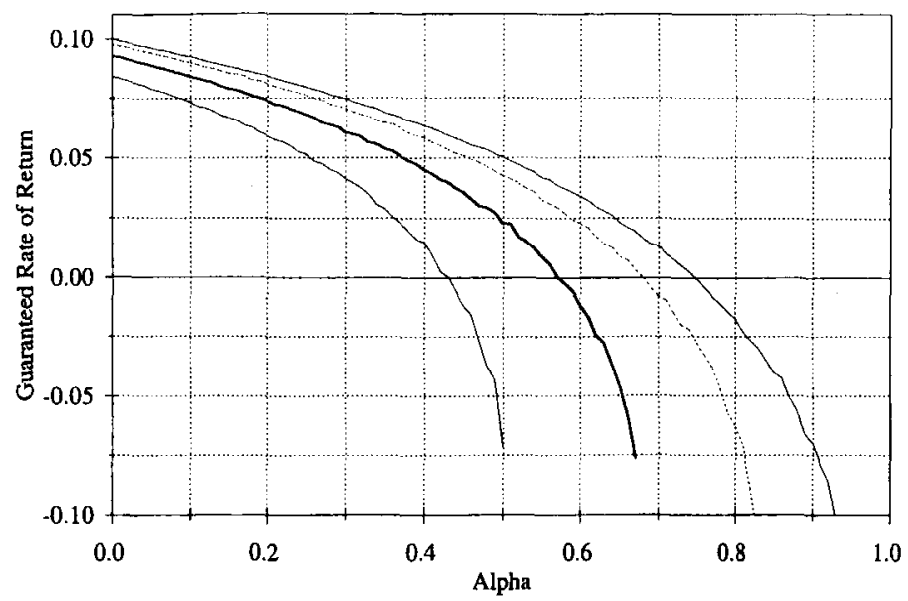

\section{Beta $=0.0 \cdots \cdots$ Beta $=0.2-$ Beta $=0.4-$ Beta $=0.6$}

Figure 16. Corresponding values of $\alpha$ and $g$ for four different values of $\beta, r=0.1$, $T=4$, and $\sigma=0.2$.

pools the bonus accounts for a large group of customers. Introducing a pooled undistributed surplus mechanism opens up a number of new and interesting issues including game theoretical considerations for the individual customers of when to enter into these life insurance contracts and when to surrender, if the contract includes a surrender option. ${ }^{6}$ We consider these new issues outside the scope of the present paper.

\section{REFERENCES}

BLACK: F. AND M. Scholes (1973): "The Pricing of Options and Corporate Liabilitics," Journol of Political Economy, $81(3): 637-654$.

BriYs, F AND F DE VARENKe (1997): "On the Risk of Life Insurance Liabilitics: Debunking Some Common Pitfalls," Journal of Risk and Insurance, 64(4).

Grosen, A. AND P. L. JøRGENSEN (1997): "Valuation of Early Excrcisable Interest Rate Guarantecs," Journal of Risk and Instrance, 64:481-503.

Mertok; R. C. (1973): "Theory of Rational Option Pricing," Bell Joumel of Economics and Management Science, 4:141-183. Reprinted in Merton (1990, Chaptcr 8).

(1990): Continuous-Time Finance, Basil Blackwell lnc., Padstow, Great Britain.

${ }^{6}$ For more on surrender options see, e.g., Grosen and Jørgensen (1997). 


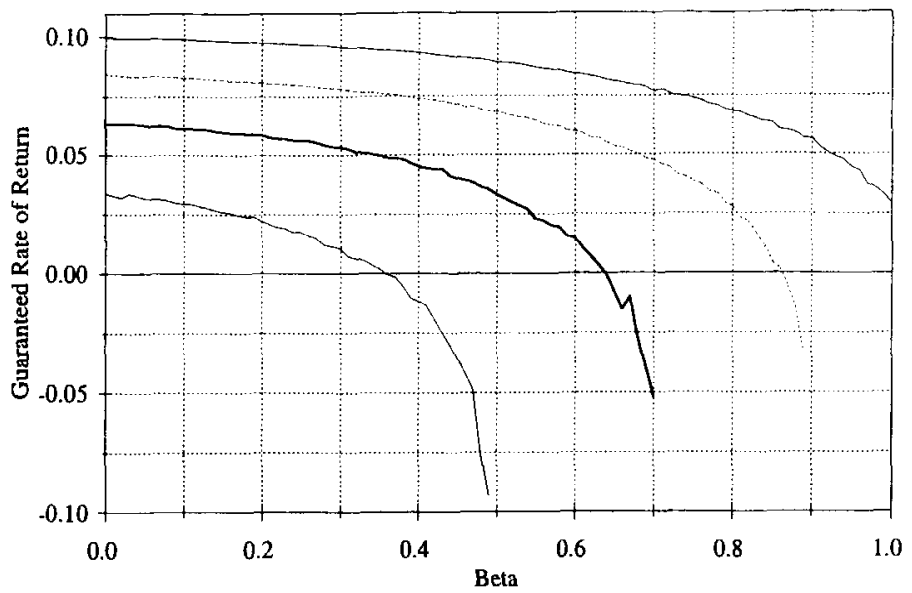

Alpha $=0.0 \cdots \ldots$ Alpha $=0.2-$ Alpha $=0.4-$ Alpha $=0.6$

FIGURE 17. Corresponding values of $\beta$ and $g$ for four different values of $\alpha, r=0.1$, $T=4$, and $\sigma=0.2$.

Miltemaes, K. R. AND S.-A. Persson (1997): "Pricing Rate of Return Guarantecs in a Heath-Jarrow-Morton Framework," Working Paper, Institute of Finance and Maragerncnt Science, Norwegian School of Economics and Busincss Administration, Helleveicn 30, N-5035 Bcrgen, Norway.

Persson, S.-A. AND K. K. Anse (1997): "Valuation of the Minimum Guaranted Return Embedded in Life Insurance Products," Journal of Risk and Irisurarice, 64(4):599-617.

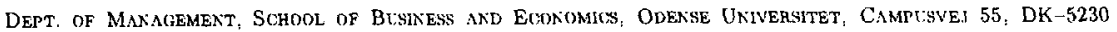
Odense M: Denmark

E-mail address: krabbusioco no. dk

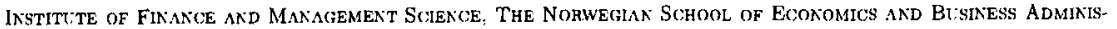
tration; Helleveies 30, N-5035 Bergen-Sandviken: Norway

E-mail address: Svein-Arne.Perssononhh.no 
